\title{
Structural stability of high entropy alloys under pressure and temperature
}

Azkar S. Ahmad, Y. Su, S. Y. Liu, K. Ståhl, Y. D. Wu, X. D. Hui, U. Ruett, O. Gutowski, K. Glazyrin, H. P. Liermann, H. Franz, H. Wang, X. D. Wang, Q. P. Cao, D. X. Zhang, and J. Z. Jiang

Citation: Journal of Applied Physics 121, 235901 (2017); doi: 10.1063/1.4984796

View online: $h$ ttp://dx.doi.org/10.1063/1.4984796

View Table of Contents: http://aip.scitation.org/toc/jap/121/23

Published by the American Institute of Physics

\section{AlP | Journal of A1P Applied Physics}

Save your money for your research.

It's now FREE to publish with us no page, color or publication charges apply.
Publish your research in the

Joumal of Applied Physics

to claim your place in applied

physics history. 


\title{
Structural stability of high entropy alloys under pressure and temperature
}

\author{
Azkar S. Ahmad, ${ }^{1}$ Y. Su, ${ }^{1}$ S. Y. Liu, ${ }^{1}$ K. Ståhl, ${ }^{2}$ Y. D. Wu, ${ }^{3}$ X. D. Hui, ${ }^{3}$ U. Ruett, ${ }^{4}$ \\ O. Gutowski, ${ }^{4}$ K. Glazyrin, ${ }^{4}$ H. P. Liermann, ${ }^{4}$ H. Franz, ${ }^{4}$ H. Wang, ${ }^{5}$ X. D. Wang, ${ }^{1}$ Q. P. Cao, ${ }^{1}$ \\ D. X. Zhang, ${ }^{6}$ and J. Z. Jiang ${ }^{1, a)}$ \\ ${ }_{1}^{1}$ International Center for New-Structured Materials and Laboratory of New-Structured Materials, State Key \\ Laboratory of Silicon Materials, School of Materials Science and Engineering, Zhejiang University, \\ Hangzhou 310027, People's Republic of China \\ ${ }^{2}$ Department of Chemistry, Building 207, Technical University of Denmark, DK-2800 Lyngby, Denmark \\ ${ }^{3}$ State Key Laboratory for Advanced Metals and Materials, University of Science and Technology Beijing, \\ Beijing 100083, People's Republic of China \\ ${ }^{4}$ Photon Science, Deutsches Elektronen-Synchrotron DESY, Notkestraße 85, D-22603 Hamburg, Germany \\ ${ }^{5}$ Institute of Nanosurface Science and Engineering, Shenzhen University, Shenzhen 518060 , \\ People's Republic of China \\ ${ }^{6}$ State Key Laboratory of Modern Optical Instrumentation, Zhejiang University, Hangzhou 310027, \\ People's Republic of China
}

(Received 25 December 2016; accepted 19 May 2017; published online 20 June 2017)

The stability of high-entropy alloys (HEAs) is a key issue before their selection for industrial applications. In this study, in-situ high-pressure and high-temperature synchrotron radiation X-ray diffraction experiments have been performed on three typical HEAs $\mathrm{Ni}_{20} \mathrm{Co}_{20} \mathrm{Fe}_{20} \mathrm{Mn}_{20} \mathrm{Cr}_{20}$, $\mathrm{Hf}_{25} \mathrm{Nb}_{25} \mathrm{Zr}_{25} \mathrm{Ti}_{25}$, and $\mathrm{Re}_{25} \mathrm{Ru}_{25} \mathrm{Co}_{25} \mathrm{Fe}_{25}$ (at. \%), having face-centered cubic (fcc), body-centered cubic (bcc), and hexagonal close-packed (hcp) crystal structures, respectively, up to the pressure of $\sim 80 \mathrm{GPa}$ and temperature of $\sim 1262 \mathrm{~K}$. Under the extreme conditions of the pressure and temperature, all three studied HEAs remain stable up to the maximum pressure and temperatures achieved. For these three types of studied HEAs, the pressure-dependence of the volume can be well described with the third order Birch-Murnaghan equation of state. The bulk modulus and its pressure derivative are found to be $88.3 \mathrm{GPa}$ and 4 for bcc- $\mathrm{Hf}_{25} \mathrm{Nb}_{25} \mathrm{Zr}_{25} \mathrm{Ti}_{25}, 193.9 \mathrm{GPa}$ and 5.9 for fcc- $\mathrm{Ni}_{20} \mathrm{Co}_{20} \mathrm{Fe}_{20} \mathrm{Mn}_{20} \mathrm{Cr}_{20}$, and $304.6 \mathrm{GPa}$ and 3.8 for hcp- $\mathrm{Re}_{25} \mathrm{Ru}_{25} \mathrm{Co}_{25} \mathrm{Fe}_{25} \mathrm{HEAs}$, respectively. The thermal expansion coefficient for the three studied HEAs is found to be in the order as follows: fcc- $\mathrm{Ni}_{20} \mathrm{Co}_{20} \mathrm{Fe}_{20} \mathrm{Mn}_{20} \mathrm{Cr}_{20}>$ bcc- $\mathrm{Hf}_{25} \mathrm{Nb}_{25} \mathrm{Zr}_{25} \mathrm{Ti}_{25} \approx$ hcp- $\mathrm{Re}_{25} \mathrm{Ru}_{25} \mathrm{Co}_{25} \mathrm{Fe}_{25}$. Published by AIP Publishing. [http://dx.doi.org/10.1063/1.4984796]

\section{INTRODUCTION}

High entropy alloys (HEAs) are relatively a new class of metallic materials developed in the last decade. Nowadays, the HEAs have attracted great attention of the materials science community due to their chemical compositions, microstructures, and fascinating properties. ${ }^{1-18}$ HEAs are generally termed as solid solution alloys that contain more than four principal elements in equal or nearly equal atomic percentage. ${ }^{1}$ These alloys are, therefore, compositionally very different from the other conventional alloys, which were termed as multicomponent alloys by Cantor et al., ${ }^{2}$ while $\mathrm{Yeh}^{18}$ named them as high entropy alloys. Despite the critics raised by Pickering and Jones, ${ }^{19}$ the discovery of HEAs has opened a new strategy of materials design.

It is of no doubt that HEAs have demonstrated unusual properties and are promising as potential structural and functional materials. Nevertheless, the understanding of the fundamentals of HEAs is still a challenging issue for materials scientists. One of the problems is due to the lack of the thermodynamic and kinetic data for the multi-component systems which are located at the center part of the related phase diagrams. Till now, complete phase diagrams are available

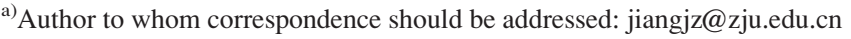

only for the binary and ternary alloys but scarce for the HEAs. Apart from the phase diagrams, another keynote in studying HEAs is to characterize their structure under the extreme conditions of pressure and temperature considering that such knowledge is of particular importance for their engineering applications. With regard to this, the present work is focused on the structural stability of three typical HEAs with fcc, bcc, and hcp crystal structures under extreme conditions.

Under extreme pressure and temperature, the behaviors of intermetallic compounds, glasses, pure metals, and a mixture of two or three metallic elements have been heavily studied. For example, metal-to-semiconductor ${ }^{20}$ metalto-insulator, ${ }^{21}$ liquid-to-liquid, ${ }^{22}$ amorphous-to-amorphous, ${ }^{23}$ and amorphous-to-crystalline ${ }^{24}$ transitions have been observed in the pure metals and amorphous and crystalline alloys of two and/or three metallic elements. However, the HEAs which contain at least four metallic elements in equal atomic proportions have been scarcely considered under the extreme conditions of temperature and pressure from the structural point of views. This is partly due to their complex compositional distribution in the ambient structure that hinders the scientist to make a reliable conclusion under extreme conditions. So far, $\mathrm{Li}$ et al. have made the only attempt to study (fcc + bcc)-AlCoCrCuFeNi HEA under the 
extreme condition of pressure. But this study was only limited to the equation of state up to the pressure of $\sim 24 \mathrm{GPa}^{25}$ Till date, a systematic and comparative study on HEAs with different phases has never been made under extreme conditions of pressure and temperature. Here, using in-situ synchrotron XRD, we explore high-temperature and highpressure behaviors of fcc- $\mathrm{Ni}_{20} \mathrm{Co}_{20} \mathrm{Fe}_{20} \mathrm{Mn}_{20} \mathrm{Cr}_{20}$, bcc$\mathrm{Hf}_{25} \mathrm{Nb}_{25} \mathrm{Zr}_{25} \mathrm{Ti}_{25}$, and hcp- $\mathrm{Re}_{25} \mathrm{Ru}_{25} \mathrm{Co}_{25} \mathrm{Fe}_{25}$ HEAs. Our results reveal that three typical HEAs exhibit tremendous stability of HEAs up to the highest pressure and temperature achieved.

\section{EXPERIMENTAL METHODS}

Synchrotron radiation XRD measurements were performed in a Mao-Bell type diamond anvil cell (DAC) with a culet of $300 \mu \mathrm{m}$ in diameter. The sample chamber was a hole of $\sim 120 \mu \mathrm{m}$ diameter drilled in a pre-indented Re gasket. The specimen was loaded into the sample chamber along with ruby as a standard for pressure calibration. Ne was used as a pressure-transmitting medium for the in-situ high pressure XRD measurements. In-situ under high pressure angledispersive XRD measurements were performed at the Extreme Conditions Beamline (ECB) P02.2, PETRAIII, DESY, Hamburg, Germany. The wavelength of the synchrotron radiation was adjusted to $0.2952 \AA$. Two-dimensional diffraction patterns were collected using a Perkin Elmer XRD 1621 ScIbonded amorphous silicon 2D detector $(2048 \times 2048$ pixels, $200 \times 200 \mu \mathrm{m}$ pixel size) mounted orthogonal to the direction of the incident X-ray beam. The $\mathrm{CeO}_{2}$ standard (NIST 674b) was used to calibrate the sample-to-detector distance and tilt of the detector relative to the beam path. The samples were exposed to an X-ray beam with a diameter of $8(\mathrm{H}) \times 3(\mathrm{~V})$ $\mu \mathrm{m}^{2}$ for $1 \mathrm{~min}$.

For high temperature experiments, small slices of the HEAs were sealed in a thin-walled quartz capillary with the diameter of $\sim 1.5 \mathrm{~mm}$ after evacuation to a vacuum of $10^{-3} \mathrm{~Pa}$. In-situ high-temperature angle-dispersive XRD measurements were performed at beamline P07, PETRAIII, DESY, Hamburg, Germany. Heating was performed using intense lamps which were held surrounding the sample container. Silicon lattice parameters were used to calibrate the temperature. The heating rate was adjusted to $\sim 20 \mathrm{~K} / \mathrm{min}$. The wavelength of synchrotron radiation was adjusted to $0.1256 \AA$. The sample was exposed to the X-ray beam of diameter $500(\mathrm{H}) \times 500(\mathrm{~V}) \mu \mathrm{m}^{2}$ for $1 \mathrm{~s}$. The two-dimensional XRD patterns were integrated into $Q$-space using software package Fit2D. ${ }^{26}$

\section{RESULTS AND DISCUSSION}

Figure 1(a) shows the XRD patterns for fcc- $\mathrm{Ni}_{20} \mathrm{Co}_{20}$ $\mathrm{Fe}_{20} \mathrm{Mn}_{20} \mathrm{Cr}_{20}$ HEA during compression from $0.2 \mathrm{GPa}$ to $48.9 \mathrm{GPa}$. It can be seen that during compression up to $48.9 \mathrm{GPa}$, the crystalline fcc-phase of $\mathrm{Ni}_{20} \mathrm{Co}_{20} \mathrm{Fe}_{20} \mathrm{Mn}_{20} \mathrm{Cr}_{20}$ HEA remains stable and neither amorphization nor the phase transition has been observed. It is important to note that the XRD peaks around $13.4^{\circ}, 15.7^{\circ}$, and $16.4^{\circ}$ at $0.2 \mathrm{GPa}$ get broader and their intensity is reduced at higher pressures (e.g., at pressure $48.9 \mathrm{GPa}$ ). This behavior can be attributed to two factors; one is the occupancy of elements with different atomic sizes on one lattice and the other is the nonhydrostatic pressure at $48.9 \mathrm{GPa}$. Furthermore, we performed Rietveld refinement on each XRD pattern obtained during compression of fcc- $\mathrm{Ni}_{20} \mathrm{Co}_{20} \mathrm{Fe}_{20} \mathrm{Mn}_{20} \mathrm{Cr}_{20}$ HEA. A tiny second phase (i.e., bcc-phase) was detected during Rietveld refinement, but overall the sample remained in its original fcc-phase. It is evident from Fig. 1(b) that lattice parameter "a" of fcc- $\mathrm{Ni}_{20} \mathrm{Co}_{20} \mathrm{Fe}_{20} \mathrm{Mn}_{20} \mathrm{Cr}_{20}$ decreases gradually during compression up to $48.9 \mathrm{GPa}$. It is evident from Fig. 1(c) that the cell-volume of fcc- $\mathrm{Ni}_{20} \mathrm{Co}_{20} \mathrm{Fe}_{20} \mathrm{Mn}_{20} \mathrm{Cr}_{20}$ decreases gradually during compression up to $48.9 \mathrm{GPa}$. The pressuredependence of volume can be described by the third order Birch-Murnaghan (B-M) equation of state, which is written as follows:

$$
\begin{aligned}
P= & \frac{3}{2} B_{0}\left[\left(\frac{V_{P}}{V_{0}}\right)^{-\frac{7}{3}}-\left(\frac{V_{P}}{V_{0}}\right)^{-\frac{5}{3}}\right] \\
& \times\left\{1-\frac{3}{4}\left(4-B_{0}^{\prime}\right)\left[\left(\frac{V_{P}}{V_{0}}\right)^{-\frac{2}{3}}-1\right]\right\},
\end{aligned}
$$

where $P$ is the pressure, $V_{0}$ is the volume at zero pressure, and $V_{P}$ is the volume at pressure $P . B_{0}$ and $B_{0}^{\prime}$ are the bulk
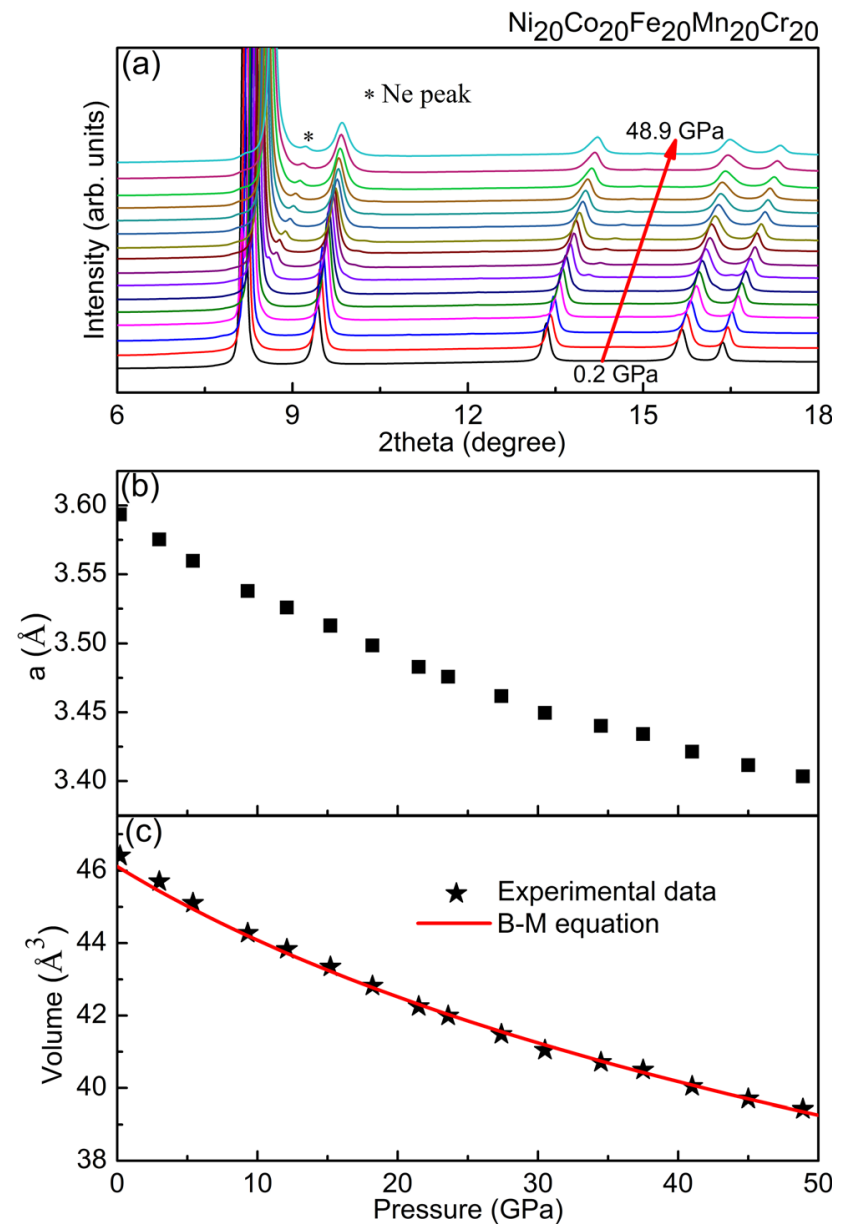

FIG. 1. High-pressure behavior of fcc- $\mathrm{Ni}_{20} \mathrm{Co}_{20} \mathrm{Fe}_{20} \mathrm{Mn}_{20} \mathrm{Cr}_{20}$ HEA via synchrotron XRD. (a) XRD patterns during compression up to $\sim 48.9 \mathrm{GPa}$. (b) Pressure-induced variation in the lattice parameter "a." (c) Equation of state of the fcc- $\mathrm{Ni}_{20} \mathrm{Co}_{20} \mathrm{Fe}_{20} \mathrm{Mn}_{20} \mathrm{Cr}_{20}$ HEA. The stars represent the experimental data points, whereas the red line is the fit for 3rd order B-M EOS. 
moduli of the sample at zero pressure and its pressure derivative, respectively. The numerical values of the fitting parameters for all three types of studied HEAs are given in Table I. The red colored line in Fig. 1(c) is the fitted curve obtained from fitting Birch-Murnaghan (B-M) equation of state (EOS). The bulk modulus of fcc- $\mathrm{Ni}_{20} \mathrm{Co}_{20} \mathrm{Fe}_{20} \mathrm{Mn}_{20} \mathrm{Cr}_{20}$ HEA is found to be $B_{0}=193.9 \mathrm{GPa}$ and its pressure derivative is found to be $B_{0}^{\prime}=5.8$. From Fig. 1, it is confirmed that fcc- $\mathrm{Ni}_{20} \mathrm{Co}_{20} \mathrm{Fe}_{20} \mathrm{Mn}_{20} \mathrm{Cr}_{20}$ HEA remains stable up to the highest pressure achieved (i.e., $\sim 48.9 \mathrm{GPa}$ ) and there is no evidence of amorphization and/or phase transition.

Figure 2(a) shows the XRD patterns for the hcp$\mathrm{Re}_{25} \mathrm{Ru}_{25} \mathrm{Co}_{25} \mathrm{Fe}_{25}$ HEA during compression from $0.9 \mathrm{GPa}$ to $80.4 \mathrm{GPa}$. During compression up to $\sim 80.4 \mathrm{GPa}$, the hcp- $\mathrm{Re}_{25} \mathrm{Ru}_{25} \mathrm{Co}_{25} \mathrm{Fe}_{25}$ HEA remains stable and neither amorphization nor the phase transition has been observed. It is evident that during compression up to $80.4 \mathrm{GPa}$, the lattice parameters "a" [lower panel, Fig. 2(b)] and "c" [upper panel, Fig. 2(b)] of hcp- $\mathrm{Re}_{25} \mathrm{Ru}_{25} \mathrm{Co}_{25} \mathrm{Fe}_{25}$ decrease gradually without any observable jump. Figure 2(c) shows the pressure-induced variations in the cell volume of the hcp$\mathrm{Re}_{25} \mathrm{Ru}_{25} \mathrm{Co}_{25} \mathrm{Fe}_{25}$ HEA. Again, no sudden jump is observed in pressure-induced volume changes during the compression up to $80.4 \mathrm{GPa}$. From the inset of Fig. 2(c), it is found that the ratio of "a/c" for hcp- $\mathrm{Re}_{25} \mathrm{Ru}_{25} \mathrm{Co}_{25} \mathrm{Fe}_{25}$ HEA slightly decreases upon compression. The experimental data points in Fig. 2(c) were well fitted by the B-M EOS [i.e., Eq. (1)] as indicated by a red colored line. The bulk modulus of $\mathrm{Re}_{25} \mathrm{Ru}_{25} \mathrm{Co}_{25} \mathrm{Fe}_{25} \mathrm{HEA}$ and its pressure derivative are found to be $B_{0}=304.6 \mathrm{GPa}$ and $B_{0}^{\prime}=3.8$, respectively. It is confirmed from Fig. 2 that hcp- $\mathrm{Re}_{25} \mathrm{Ru}_{25} \mathrm{Co}_{25} \mathrm{Fe}_{25}$ HEA remains stable up to the highest pressure achieved (i.e., $\sim 80.4 \mathrm{GPa}$ ) and there is no signature of the amorphization and/or phase transition. Similar to fcc- $\mathrm{Ni}_{20} \mathrm{Co}_{20} \mathrm{Fe}_{20} \mathrm{Mn}_{20} \mathrm{Cr}_{20}$ and hcp- $\mathrm{Re}_{25} \mathrm{Ru}_{25} \mathrm{Co}_{25} \mathrm{Fe}_{25}$ HEAs, we also performed in-situ high-pressure XRD measurements on bcc- $\mathrm{Hf}_{25} \mathrm{Nb}_{25} \mathrm{Zr}_{25} \mathrm{Ti}_{25}$ HEA up to $50.8 \mathrm{GPa}$ (not shown here due to the page limit). Again, during compression up to $50.8 \mathrm{GPa}$, bcc- $\mathrm{Hf}_{25} \mathrm{Nb}_{25}$ $\mathrm{Zr}_{25} \mathrm{Ti}_{25}$ HEA remained stable and neither amorphization nor the phase transition was observed. In Table I, the bulk modulus and its pressure derivative for bcc- $\mathrm{Hf}_{25} \mathrm{Nb}_{25} \mathrm{Zr}_{25}$

TABLE I. The numerical values of the unit cell volume $\left(\mathrm{V}_{0}\right)$, bulk modulus $\left(\mathrm{B}_{0}\right)$, pressure derivative of the bulk modulus $\left(\mathrm{B}^{\prime}{ }_{0}\right)$, ambient conditions lattice parameters $\left(\mathrm{a}_{0}\right.$ and $\left.\mathrm{c}_{0}\right)$, and thermal expansion coefficient $(\alpha)$ for the three studied HEAs are listed. The numerical values of $\mathrm{a}_{\mathrm{av}}$ and $\mathrm{c}_{\mathrm{av}}$ are taken from bcc-Nb and fcc-Ni and the average value of hcp-Re, hcp-Ru, and hcp-Co.

\begin{tabular}{lccc}
\hline \hline Parameter & $\begin{array}{c}\mathrm{Hf}_{25} \mathrm{Nb}_{25} \\
\mathrm{Zr}_{25} \mathrm{Ti}_{25}\end{array}$ & $\begin{array}{c}\mathrm{Ni}_{20} \mathrm{Co}_{20} \mathrm{Fe}_{20} \\
\mathrm{Mn}_{20} \mathrm{Cr}_{20}\end{array}$ & $\begin{array}{c}\mathrm{Re}_{25} \mathrm{Ru}_{25} \\
\mathrm{Co}_{25} \mathrm{Fe}_{25}\end{array}$ \\
\hline $\mathrm{V}_{0}\left(\AA^{3}\right)$ & 40.0 & 46.1 & 26.0 \\
$\mathrm{~B}_{0}(\mathrm{GPa})$ & $88.3( \pm 13.5)$ & $193.9( \pm 7.3)$ & $304.5( \pm 2.3)$ \\
$\mathrm{B}^{\prime}{ }_{0}$ & $4.0( \pm 1.0)$ & $5.9( \pm 0.6)$ & $3.8( \pm 0.1)$ \\
$\mathrm{a}_{0}(\AA)$ at $\mathrm{RT}$ & 3.4 & 3.6 & 2.65 \\
$\mathrm{c}_{0}(\AA)$ at $\mathrm{RT}$ & $\ldots$ & $\ldots$ & 4.25 \\
$\mathrm{a}_{\text {av }}(\AA)$ at $\mathrm{RT}$ & 3.30 & 3.52 & 2.66 \\
$\mathrm{c}_{\text {av }}(\AA)$ at $\mathrm{RT}$ & $\ldots$ & $\ldots$ & 4.27 \\
$\alpha\left(\times 10^{-5} \mathrm{~K}^{-1}\right)$ & 2.3 & 3.6 & 2.1 \\
\hline \hline
\end{tabular}
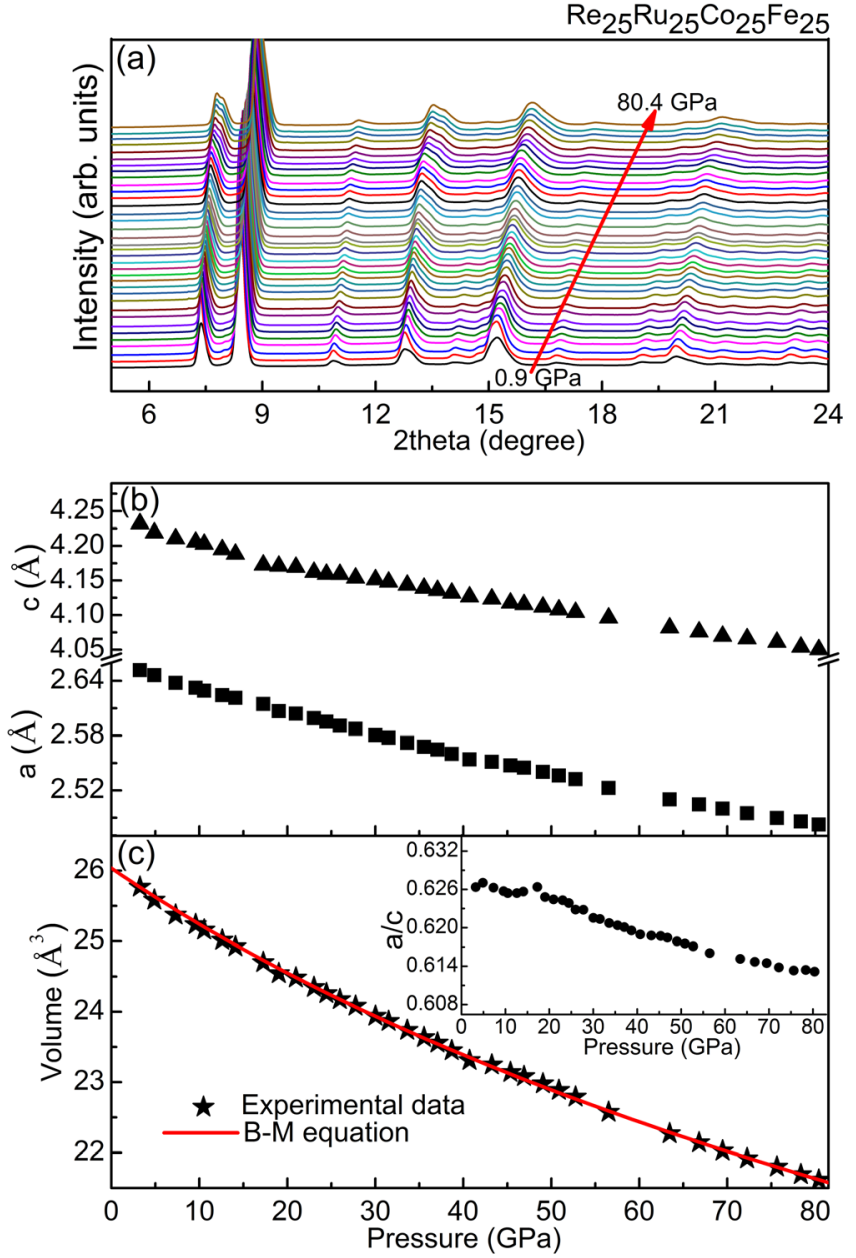

FIG. 2. High-pressure behavior of hcp- $\mathrm{Re}_{25} \mathrm{Ru}_{25} \mathrm{Co}_{25} \mathrm{Fe}_{25} \mathrm{HEA}$ via synchrotron XRD. (a) XRD patterns during compression up to $\sim 80.4 \mathrm{GPa}$. (b) Lower panel demonstrates the variation in the lattice parameter " $\mathrm{a}$ " and the upper panel shows the variation in the lattice parameter "c," which were estimated by the Rietveld refinement of each XRD pattern recorded. (c) Equation of state of the hcp- $\mathrm{Re}_{25} \mathrm{Ru}_{25} \mathrm{Co}_{25} \mathrm{Fe}_{25} \mathrm{HEA}$. The stars represent the experimental data points, whereas the red line is the fit for 3rd order B-M EOS. The inset shows pressure-induced the variations in the "a/c."

$\mathrm{Ti}_{25}$ HEA are listed as $B_{0}=88.3 \mathrm{GPa}$ and $B_{0}^{\prime}=4$, respectively. Due to the relatively small value of bulk modulus, relatively large compressibility is expected under pressure for bcc- $\mathrm{Hf}_{25} \mathrm{Nb}_{25} \mathrm{Zr}_{25} \mathrm{Ti}_{25}$ HEA as compared to those for fcc$\mathrm{Ni}_{20} \mathrm{Co}_{20} \mathrm{Fe}_{20} \mathrm{Mn}_{20} \mathrm{Cr}_{20}$ and hcp- $\mathrm{Re}_{25} \mathrm{Ru}_{25} \mathrm{Co}_{25} \mathrm{Fe}_{25}$ HEAs, as listed in Table I. A careful analysis on the relative change in unit cell volume with pressure has been made for three studied HEAs, and it is found that the relative compressibility of the three HEAs is in the order as follows: bcc- $\mathrm{Hf}_{25} \mathrm{Nb}_{25} \mathrm{Zr}_{25}$ $\mathrm{Ti}_{25}>$ fcc- $\mathrm{Ni}_{20} \mathrm{Co}_{20} \mathrm{Fe}_{20} \mathrm{Mn}_{20} \mathrm{Cr}_{20}>$ hcp $-\mathrm{Re}_{25} \mathrm{Ru}_{25} \mathrm{Co}_{25} \mathrm{Fe}_{25}$.

Figures 3(a)-3(c) show the XRD patterns for bcc$\mathrm{Hf}_{25} \mathrm{Nb}_{25} \mathrm{Zr}_{25} \mathrm{Ti}_{25}$, fcc- $\mathrm{Ni}_{20} \mathrm{Co}_{20} \mathrm{Fe}_{20} \mathrm{Mn}_{20} \mathrm{Cr}_{20}$, and hcp- $\mathrm{Re}_{25}$ $\mathrm{Ru}_{25} \mathrm{Co}_{25} \mathrm{Fe}_{25}$ HEAs during heating up to $1102.3 \mathrm{~K}$, $1060.5 \mathrm{~K}$, and $1262.5 \mathrm{~K}$, respectively. It is clear that upon heating all three studied HEAs remain stable up to the maximum temperature achieved, and neither amorphization nor the phase transition has been observed. Figures 3(d)-3(f) show the temperature-induced variations in lattice parameter "a" (i.e., linear thermal expansion) of bcc- $\mathrm{Hf}_{25} \mathrm{Nb}_{25} \mathrm{Zr}_{25} \mathrm{Ti}_{25}$, fcc- $\mathrm{Ni}_{20} \mathrm{Co}_{20} \mathrm{Fe}_{20} \mathrm{Mn}_{20} \mathrm{Cr}_{20}$, and hcp- $\mathrm{Re}_{25} \mathrm{Ru}_{25} \mathrm{Co}_{25} \mathrm{Fe}_{25}$ 

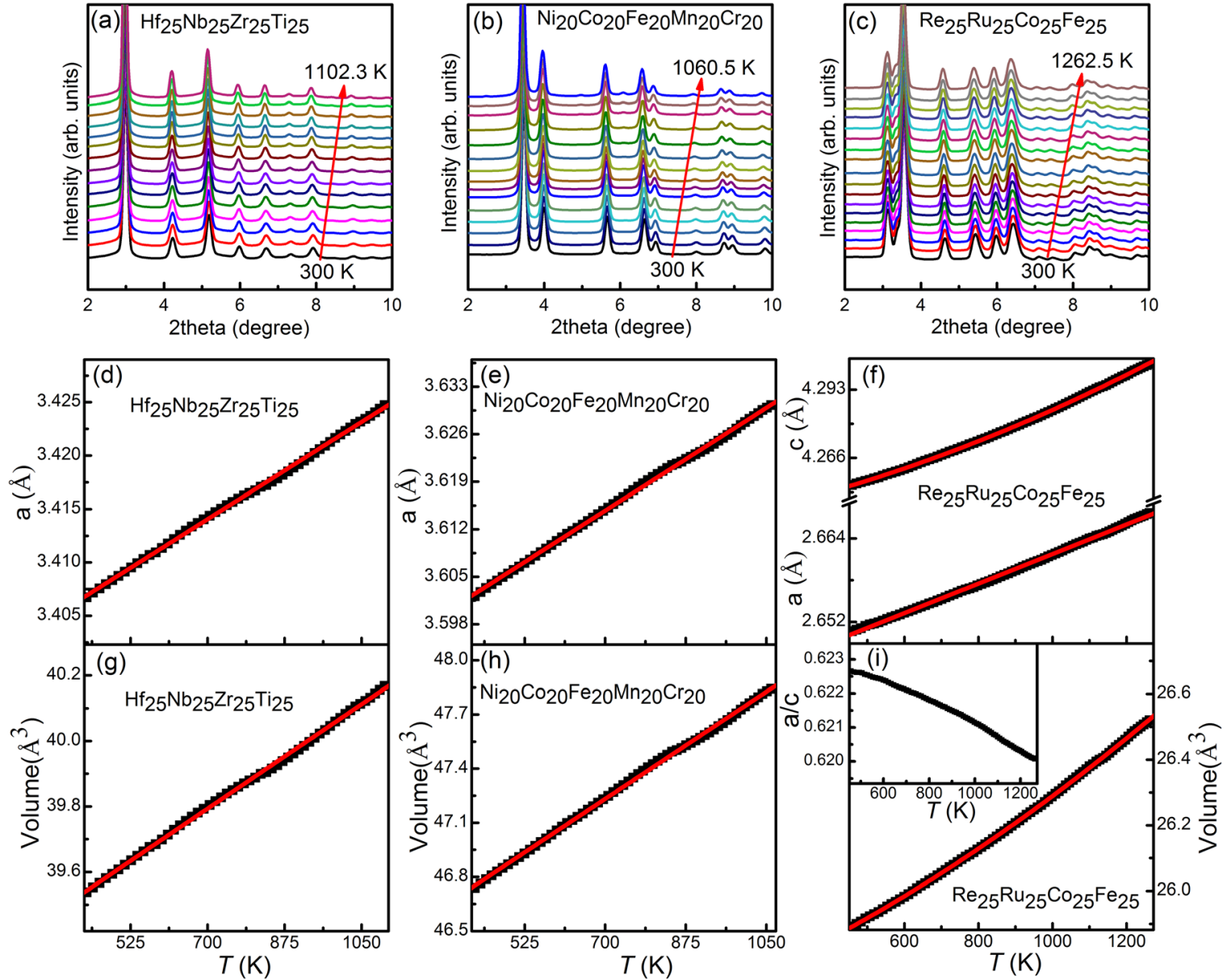

FIG. 3. High-temperature behaviors of HEAs via synchrotron XRD. (a) XRD patterns of bcc- $\mathrm{Hf}_{25} \mathrm{Nb}_{25} \mathrm{Zr}_{25} \mathrm{Ti}_{25} \mathrm{HEA}$ during heating up to $\sim 1102.3 \mathrm{~K}$. (b) XRD patterns of fcc- $\mathrm{Ni}_{20} \mathrm{Co}_{20} \mathrm{Fe}_{20} \mathrm{Mn}_{20} \mathrm{Cr}_{20}$ HEA during heating up to $\sim 1060.5 \mathrm{~K}$. (c) XRD patterns of hcp- $\mathrm{Re}_{25} \mathrm{Ru}_{25} \mathrm{Co}_{25} \mathrm{Fe}_{25} \mathrm{HEA}$ during heating up to $\sim 1262.5 \mathrm{~K}$. (d) Linear thermal-expansion of the lattice parameter "a" of bcc- $\mathrm{Hf}_{25} \mathrm{Nb}_{25} \mathrm{Zr}_{25} \mathrm{Ti}_{25}$ HEA. The red line is linear fit to the experimental data points. (e) Linear thermal-expansion of the lattice parameter "a" of fcc- $\mathrm{Ni}_{20} \mathrm{Co}_{20} \mathrm{Fe}_{20} \mathrm{Mn}_{20} \mathrm{Cr}_{20}$ HEA. The red line is a linear fit to the experimental data points. (f) Thermal-expansion in the lattice parameters "a" (lower panel) and "c" (upper panel) of hcp- $\mathrm{Re}_{25} \mathrm{Ru}_{25} \mathrm{Co}_{25} \mathrm{Fe}_{25} \mathrm{HEA}$. The red lines are fits to the experimental data points by a linear equation and $\mathrm{y}=\mathrm{b}_{0}+\mathrm{b}_{1} \mathrm{x}+\mathrm{b}_{2} \mathrm{x}^{2}$ for the lattice parameters " $\mathrm{a}$ " and "c," respectively. (g) Volumetric thermal-expansion in the unit cell of bcc- $\mathrm{Hf}_{25} \mathrm{Nb}_{25} \mathrm{Zr}_{25} \mathrm{Ti}_{25} \mathrm{HEA}$. The red line is a linear fit to the experimental data points. (h) Volumetric thermal-expansion in the unit cell of fcc$\mathrm{Ni}_{20} \mathrm{Co}_{20} \mathrm{Fe}_{20} \mathrm{Mn}_{20} \mathrm{Cr}_{20}$ HEA. The red line is linear fit to the experimental data points. (i) Volumetric thermal-expansion in hcp- $\mathrm{Re}_{25} \mathrm{Ru}_{25} \mathrm{Co}_{25} \mathrm{Fe}_{25} \mathrm{HEA}$. The red line is fit to the experimental data points and follows the equation $\mathrm{y}=\mathrm{b}_{0}+\mathrm{b}_{1} \mathrm{x}+\mathrm{b}_{2} \mathrm{x}^{2}$. The inset shows temperature-induced variations in the " $\mathrm{a} / \mathrm{c}$ " of the hcp- $\mathrm{Re}_{25} \mathrm{Ru}_{25} \mathrm{Co}_{25} \mathrm{Fe}_{25} \mathrm{HEA}$

(lower panel) HEAs during heating up $1102.3 \mathrm{~K}, 1060.5 \mathrm{~K}$, and $1262.5 \mathrm{~K}$, respectively. The solid lines in red are the linear fits to the experimental data points. Figure 3(f) (upper panel) shows the temperature-induced variations in the lattice parameter "c" of the hcp- $\mathrm{Re}_{25} \mathrm{Ru}_{25} \mathrm{Co}_{25} \mathrm{Fe}_{25}$ HEA. The red line is the fit to the experimental data points. Surprisingly, it is found that the temperature-induced variations in lattice parameter "c" do not follow a linear relation and rather can be fitted by an equation $y=b_{0}+b_{1} x+b_{2} x^{2}$, where " $y$ " is the value of the lattice parameter "c" at temperature "x," and $b_{0}, b_{1}$, and $b_{2}$ are the fitting parameters. Figures 3(g)-3(i) show the temperature-induced variations in the cell-volume (i.e., volumetric thermal expansion) of bcc- $\mathrm{Hf}_{25} \mathrm{Nb}_{25} \mathrm{Zr}_{25} \mathrm{Ti}_{25}$, fcc- $\mathrm{Ni}_{20} \mathrm{Co}_{20} \mathrm{Fe}_{20} \mathrm{Mn}_{20} \mathrm{Cr}_{20}$, and hcp$\mathrm{Re}_{25} \mathrm{Ru}_{25} \mathrm{Co}_{25} \mathrm{Fe}_{25}$ HEAs during heating up $1102.3 \mathrm{~K}$, $1060.5 \mathrm{~K}$, and $1262.5 \mathrm{~K}$ HEAs, respectively. The red lines are the fits to the experimental data points which follow the linear relation for the bcc- $-\mathrm{Hf}_{25} \mathrm{Nb}_{25} \mathrm{Zr}_{25} \mathrm{Ti}_{25}$ and fcc- $\mathrm{Ni}_{20} \mathrm{Co}_{20} \mathrm{Fe}_{20} \mathrm{Mn}_{20} \mathrm{Cr}_{20}$, and a non-linear relation for hcp- $\mathrm{Re}_{25} \mathrm{Ru}_{25} \mathrm{Co}_{25} \mathrm{Fe}_{25}$ HEA. Figure 3(i) (inset) shows the temperature-induced variations in "a/c" of the hcp$\mathrm{Re}_{25} \mathrm{Ru}_{25} \mathrm{Co}_{25} \mathrm{Fe}_{25} \mathrm{HEA}$. It is clear that a/c slightly decreases upon heating up to the maximum temperature achieved (i.e., 1262.5 K). From Figs. 3(a)-3(i), it is confirmed that all three studied HEAs remain stable up to the highest values of the temperature achieved, and there is no signature of the amorphization and/or phase transition.

Furthermore, we calculated the volume thermalexpansion coefficient $(\alpha)$ for three studied HEAs (Table I), which is found to be in the order as follows: fcc- $-\mathrm{Ni}_{20} \mathrm{Co}_{20}$ $\mathrm{Fe}_{20} \mathrm{Mn}_{20} \mathrm{Cr}_{20}>$ bcc- $\mathrm{Hf}_{25} \mathrm{Nb}_{25} \mathrm{Zr}_{25} \mathrm{Ti}_{25} \approx$ hcp- $\mathrm{Re}_{25} \mathrm{Ru}_{25} \mathrm{Co}_{25}$ $\mathrm{Fe}_{25}$. The slight non-linear volume expansion for the hcpHEA was fitted by a polynomial function of $y=b_{0}+b_{1} x$ $+b_{2} x^{2}$, in which the parameter $b_{1}$ has a major contribution, whereas the contribution from the term $\mathrm{b}_{2} \mathrm{x}^{2}$ is relatively small. Therefore, upon heating the HEA with the largest initial cell volume (i.e., fcc- $\mathrm{Ni}_{20} \mathrm{Co}_{20} \mathrm{Fe}_{20} \mathrm{Mn}_{20} \mathrm{Cr}_{2}$ ) expands at a higher rate than the other two HEAs. This scenario is also 
consistent with order of the melting points of three studied HEAs, which is in the order as follows: fcc$\mathrm{Ni}_{20} \mathrm{Co}_{20} \mathrm{Fe}_{20} \mathrm{Mn}_{20} \mathrm{Cr}_{20}>$ bcc- $\mathrm{Hf}_{25} \quad \mathrm{Nb}_{25} \mathrm{Zr}_{25} \mathrm{Ti}_{25} \approx$ hcp$\mathrm{Re}_{25} \mathrm{Ru}_{25} \mathrm{Co}_{25} \mathrm{Fe}_{25}$. Generally, pure metals with lower melting points expand at higher rate, and in the same way, the HEA with lower melting point (i.e., fcc$\left.\mathrm{Ni}_{20} \mathrm{Co}_{20} \mathrm{Fe}_{20} \mathrm{Mn}_{20} \mathrm{Cr}_{20}\right)$ has a higher thermal-expansion coefficient than the other two HEAs. It means that under extreme conditions of temperature, fcc- $\mathrm{Ni}_{20} \mathrm{Co}_{20} \mathrm{Fe}_{20} \mathrm{Mn}_{20}$ $\mathrm{Cr}_{20}$ HEA is the most affected than bcc- $\mathrm{Hf}_{25} \mathrm{Nb}_{25} \mathrm{Zr}_{25} \mathrm{Ti}_{25}$ and hcp- $\mathrm{Re}_{25} \mathrm{Ru}_{25} \mathrm{Co}_{25} \mathrm{Fe}_{25}$ HEAs. On the other hand, the bulk moduli of three studied HEAs (Table I) are found to be in the order as follows: hcp- $\mathrm{Re}_{25} \mathrm{Ru}_{25} \mathrm{Co}_{25} \mathrm{Fe}_{25}>\mathrm{fcc}-\mathrm{Ni}_{20}$ $\mathrm{Co}_{20} \mathrm{Fe}_{20} \mathrm{Mn}_{20} \mathrm{Cr}_{20}>$ bcc- $\mathrm{Hf}_{25} \mathrm{Nb}_{25} \mathrm{Zr}_{25} \mathrm{Ti}_{25}$. These results suggest a relation with the stiffness of each potential curve in the left-side below the equilibrium point of the three studied HEAs, i.e., the degree of stiffness of each potential curve is expected to be in the order as follows: hcp- $\mathrm{Re}_{25}$ $\mathrm{Ru}_{25} \mathrm{Co}_{25} \mathrm{Fe}_{25}>$ fcc- $\mathrm{Ni}_{20} \mathrm{Co}_{20} \mathrm{Fe}_{20} \mathrm{Mn}_{20} \mathrm{Cr}_{20}>$ bcc- $-\mathrm{Hf}_{25} \mathrm{Nb}_{25}$ $\mathrm{Zr}_{25} \mathrm{Ti}_{25}$. Furthermore, it is important to mention that the average values of lattice constants of pure metals with bcc phases (i.e., bcc-Nb) in bcc- $\mathrm{Hf}_{25} \mathrm{Nb}_{25} \mathrm{Zr}_{25} \mathrm{Ti}_{25}$ and the average values of lattice constants of pure metals with fcc phases (i.e., fcc-Ni) in fcc- $\mathrm{Ni}_{20} \mathrm{Co}_{20} \mathrm{Fe}_{20} \mathrm{Mn}_{20} \mathrm{Cr}_{20}$ at ambient conditions are $3.30 \AA$ and $3.52 \AA$, respectively (Table I). These values are very similar to lattice constants for bcc$\mathrm{Hf}_{25} \mathrm{Nb}_{25} \mathrm{Zr}_{25} \mathrm{Ti}_{25}$ (i.e., 3.4 $\AA$ ) and fcc- $\mathrm{Ni}_{20} \mathrm{Co}_{20} \mathrm{Fe}_{20} \mathrm{Mn}_{20}$ $\mathrm{Cr}_{20}$ (i.e., $3.6 \AA$ ) HEAs. For hcp- $\mathrm{Re}_{25} \mathrm{Ru}_{25} \mathrm{Co}_{25} \mathrm{Fe}_{25} \mathrm{HEA}$, the lattice constants are $\mathrm{a}=2.65 \AA$ and $\mathrm{c}=4.25 \AA$, which are similar to the average lattice constants (i.e., $\mathrm{a}_{\mathrm{av}}=2.658 \AA$ and $\mathrm{c}_{\mathrm{av}}=4.269 \AA$ ) calculated by taking an average over the lattice constants of pure constituent metals, i.e., hcp-Re, hcp-Ru, and hcp-Co. The bulk moduli of hcp-Re, hcp-Ru, and hcp-Co at ambient conditions are 370,220 , and $180 \mathrm{GPa}$, respectively. By taking an average over the bulk moduli of these pure metals, their average bulk modulus turns out to be $257 \mathrm{GPa}$, which is larger than the bulk modulus of fcc-Ni (180 GPa) and bcc-Nb (170 GPa).

\section{CONCLUSIONS}

In summary, we have performed in-situ high-pressure and high-temperatures XRD measurements on bcc$\mathrm{Hf}_{25} \mathrm{Nb}_{25} \mathrm{Zr}_{25} \mathrm{Ti}_{25}$, fcc- $\mathrm{Ni}_{20} \mathrm{Co}_{20} \mathrm{Fe}_{20} \mathrm{Mn}_{20} \mathrm{Cr}_{20}$, and hcp$\mathrm{Re}_{25} \mathrm{Ru}_{25} \mathrm{Co}_{25} \mathrm{Fe}_{25}$ HEAs. Under both high-pressure and high-temperature conditions, HEAs remain stable and no signature of amorphization and/or phase transition is observed. However, the relative structural stability of three studied HEAs is found to follow different trends under high-pressure and high-temperature conditions. Under high-pressure conditions, the monotonic decrease in lattice parameters and cellvolume has been observed for the HEAs, and pressuredependence of volume can be well reproduced by third order B-M EOS. Upon compression, the rate of decrease in cellvolume for three studied HEAs is found to be in the order: bcc- $-\mathrm{Hf}_{25} \mathrm{Nb}_{25} \mathrm{Zr}_{25} \mathrm{Ti}_{25}>$ fcc- $\mathrm{Ni}_{20} \mathrm{Co}_{20} \mathrm{Fe}_{20} \mathrm{Mn}_{20} \mathrm{Cr}_{20}>$ hcp$\mathrm{Re}_{25} \mathrm{Ru}_{25} \mathrm{Co}_{25} \mathrm{Fe}_{25}$. Under high-temperature conditions, a monotonic increase in the lattice parameter and cell volume has been observed for three studied HEAs, and the rate of thermal-expansion is found to be in the order: fcc$\mathrm{Ni}_{20} \mathrm{Co}_{20} \mathrm{Fe}_{20} \mathrm{Mn}_{20} \mathrm{Cr}_{20}>$ bcc- $-\mathrm{Hf}_{25} \mathrm{Nb}_{25} \mathrm{Zr}_{25} \mathrm{Ti}_{25} \approx$ hcp$\mathrm{Re}_{25} \mathrm{Ru}_{25} \mathrm{Co}_{25} \mathrm{Fe}_{25}$. In short, the HEAs remain stable under both extreme pressure and temperature conditions and this structural stability points out the potential application of HEAs under extreme conditions.

\section{ACKNOWLEDGMENTS}

Financial support from the National Natural Science Foundation of China (Nos. 51371157, U1432105, U1432110, U1532115, 51671170, and 51671169), the National Key Research and Development Program of China (Nos. 2016YFB0701203 and 2016YFB0700201), the Natural Science Foundation of Zhejiang Province (Grant Nos. Z1110196 and Y4110192), and the Fundamental Research Funds for the Central Universities is gratefully acknowledged.

${ }^{1}$ Y. Zhang et al., "Microstructures and properties of high-entropy alloys," Prog. Mater. Sci. 61, 1-93 (2014).

${ }^{2}$ B. Cantor et al., "Microstructural development in equiatomic multicomponent alloys," Mater. Sci. Eng.: A 375-377, 213-218 (2004).

${ }^{3}$ X. Yang, Y. Zhang, and P. K. Liaw, "Microstructure and compressive properties of NbTiVTaAlx high entropy alloys," Procedia Eng. 36, 292-298 (2012).

${ }^{4}$ Y. J. Zhou et al., "Solid solution alloys of AlCoCrFeNiTix with excellent room-temperature mechanical properties," Appl. Phys. Lett. 90(18), 181904 (2007).

${ }^{5}$ O. N. Senkov et al., "Mechanical properties of Nb 25Mo 25Ta 25W 25 and V 20Nb 20Mo 20Ta 20W 20 refractory high entropy alloys," Intermetallics 19(5), 698-706 (2011).

${ }^{6} \mathrm{~S}$. Singh et al., "Decomposition in multi-component AlCoCrCuFeNi highentropy alloy," Acta Mater. 59(1), 182-190 (2011).

${ }^{7}$ Y. Zhang et al., "Solid-solution phase formation rules for multicomponent alloys," Adv. Eng. Mater. 10(6), 534-538 (2008).

${ }^{8} \mathrm{C}$. Li et al., "Effect of alloying elements on microstructure and properties of multiprincipal elements high-entropy alloys," J. Alloys Compd. 475(1-2), 752-757 (2009).

${ }^{9}$ H. W. Chang et al., "Nitride films deposited from an equimolar Al-Cr-MoSi-Ti alloy target by reactive direct current magnetron sputtering," Thin Solid Films 516(18), 6402-6408 (2008).

${ }^{10} \mathrm{Y}$. Zhang et al., "Minor alloying behavior in bulk metallic glasses and highentropy alloys,” Sci. China Ser. G: Phys. Mech. Astron. 51(4), 427-437 (2008).

${ }^{11} \mathrm{H}$. Zhang et al., "Microstructure and properties of 6FeNiCoSiCrAlTi highentropy alloy coating prepared by laser cladding," Appl. Surf. Sci. 257(6), 2259-2263 (2011).

${ }^{12}$ B. Canton, "Stable and metastable multicomponent alloys," Ann. Chim. Sci. Mater. 32, 245-256 (2007).

${ }^{13}$ A. L. Greer, “Confusion by design," Nature 366(6453), 303-304 (1993).

${ }^{14}$ B. Cantor, F. A. M. Galano, K. B. Kim, I. C. Stone, and P. J. Warren, "Novel multicomponent alloys," J. Metastable Nanocryst. Mater. 24-25, $1-6(2005)$.

${ }^{15} \mathrm{X}$. Yang and Y. Zhang, "Prediction of high-entropy stabilized solidsolution in multi-component alloys," Mater. Chem. Phys. 132(2-3), 233-238 (2012).

${ }^{16}$ C. M. Lin and H. L. Tsai, "Evolution of microstructure, hardness, and corrosion properties of high-entropy $\mathrm{A} 10.5 \mathrm{CoCrFeNi}$ alloy," Intermetallics 19(3), 288-294 (2011).

${ }^{17}$ B. Gludovatz et al., "A fracture-resistant high-entropy alloy for cryogenic applications," Sci. 345(6201), 1153-1158 (2014).

${ }^{18} \mathrm{~J}$. W. Yeh, "Recent progress in high-entropy alloys," Ann. Chim. 31(6), 633-648 (2006).

${ }^{19}$ E. J. Pickering and N. G. Jones, "High-entropy alloys: a critical assessment of their founding principles and future prospects," Int. Mater. Rev. 61(3), 183-202 (2016).

${ }^{20}$ T. Matsuoka and K. Shimizu, "Direct observation of a pressure-induced metal-to-semiconductor transition in lithium," Nature 458(7235), 186-189 (2009). 
${ }^{21} \mathrm{X}$. Jin et al., "Crossover from metal to insulator in dense lithiumrich compound $\mathrm{CLi}_{4}$," Proc. Natl. Acad. Sci. 113(9), 2366-2369 (2016).

${ }^{22}$ A. Cadien et al., "First-order liquid-liquid phase transition in cerium," Phys. Rev. Lett. 110(12), 125503 (2013).

${ }^{23}$ Q.-S. Zeng et al., "Origin of pressure-induced polyamorphism in $\mathrm{Ce}_{75} \mathrm{Al}_{25}$ metallic glass," Phys. Rev. Lett 104(10), 105702 (2010).
${ }^{24} \mathrm{Q}$. Zeng et al., "Long-range topological order in metallic glass," Science 332(6036), 1404-1406 (2011).

${ }^{25} \mathrm{G}$. Li et al., "Equation of state of an AlCoCrCuFeNi high-entropy alloy," JOM 67(10), 2310-2313 (2015).

${ }^{26}$ A. P. Hammersley et al., "Two-dimensional detector software: From real detector to idealised image or two-theta scan," High Pressure Res. 14(4-6), 235-248 (1996). 